\title{
Effect of Xenon Arc Irradiation on Mink Hair Protein Extracted with Thioglycolate
}

\author{
Mariko TERASHIMA, Tetsuo IMAI, Yasumasa CHONAN \\ and Kunio SHIRAI ${ }^{1}$ \\ Tokyo Metropolitan Leather Technology Center, \\ Sumida-ku, Tokyo 131-0042, Japan \\ ${ }^{1}$ Scleroprotein and Leather Research Institutc, Faculty of Agriculture, \\ Tokyo University of Agriculture and Technology, \\ Fuchu-shi 183-8509, Japan
}

(Received November 6, 1998 ; Accepted February 15, 1999)

\begin{abstract}
The effect of xenon arc irradiation on the extractability and properties of mink hair protein treated with sodium thioglycolate solution was investigated. Over $50 \%$ of the intact sapphire mink hair was dissolved when treated with TG $11(0.1 \mathrm{M}$ sodium thioglycolate, $\mathrm{pH} 11)$ and TG/G-7 $(0.1 \mathrm{M}$ sodium thioglycolate, $6 \mathrm{M}$ guanidine- $\mathrm{HCl}, \mathrm{pH} 7$ ), but hardly dissolved with TG/U-7 (0.1 M sodium thioglycolate, $7 \mathrm{M}$ urea, $\mathrm{pH} 7$ ). The extractability of underfur was higher than that of guard hair with TG 11 or TG/G-7. The extractability with TG 11 or TG/G-7 was remarkably decreased in intact hair than irradiated hair. This implies that the irradiation-induced deterioration of mink hair involves the formation of some additional intermolecular or interpeptide crosslinks other than the original disulfide bridges in native hair. Amino acid analysis, SDS-PAGE and size exclusion chromatography of TG/G7 extract revealed that the irradiation of mink hair made preferentially microfibril protein insoluble, and leaves matrix protein especially high-glycine-tyrosine component soluble.
\end{abstract}

Animal Science Journal 70 (3) : 135-141, 1999

Key words : Mink hair, Xenon arc irradiation, Thioglycolate extraction

Mink fur product is one of the representative clothing materials and receives a number of consumer complaints concerning discoloration and deterioration of hair due to light exposure. The authors have started investigating the evaluation method of light deterioration in mink hair, and reported the method for estimating the amount of light induced oxidative products including cysteic acid originated from cystine residues in hair protein by FTIR microspectroscopy ${ }^{7}$.

It is known that the framework of hair is a disulfide crosslinked structure of proteins which are mainly of microfibril origin and matrix origin. These protein elements can be dissolved when the disulfide crosslinkages are cleaved by the reduction with thiols. If the oxidative damage due to light irradiation involves the formation of a number of new intermolecular or interpeptide chain crosslinks other than disulfide, the hair protein will become less soluble in thiol solution, whereas if it involves some oxidative fragmentation of peptide chain as well as oxidative disulfide cleavage it will become more soluble. These changes influence the amount and composition of protein extracted with thiols from the hair, and hence are expected to provide an index for evaluating the light deterioration of hair. To obtain a good solubility of hair keratin without affecting its molecular property, the extraction with a mixture of thiol compound and denaturant at a relatively lower temperature has been reported ${ }^{1,6)}$.

This paper described the application of a mixture of

Corresponding : Mariko TERASHIMA (fax : +81 (0) 3-3616-1676)

Anim. Sci. J. 70 (3) : 135-141, 1999 
sodium thioglycolate and guanidine hydrochloride in extracting proteins from the light irradiated mink hair and examined their properties.

\section{Materials and Methods}

\section{Mink hairs}

Frozen green skin of sapphire mink (male, 0 size) was cut into 6 portions as in Fig. 1. Guard hair and underfur were separately picked off from each portion. Hair sample from portions $a \sim f$ was separately washed with $0.1 \%$ Tween 80 (nonionic surfactant) and $1 \%$ sodium chloride, then degreased with acetone and n-hexane. The dried hair sample was cut about $3 \mathrm{~mm}$ long.

\section{Extraction of proteins ${ }^{3)}$}

Three kinds of sodium thioglycolate solvent, $0.1 \mathrm{M}$ sodium thioglycolate at pH 11 (TG 11), 0.1 M sodium thioglycolate containing $6 \mathrm{M}$ guanidine- $\mathrm{HCl}$ at $\mathrm{pH} 7$ ( $\mathrm{TG} / \mathrm{G}-7$ ) and $0.1 \mathrm{M}$ sodium thioglycolate containing $7 \mathrm{M}$ urea at $\mathrm{pH} 7$ (TG/U-7) were used for extracting proteins.

One hundred mg of hair sample was stirred with 10 $\mathrm{m} l$ of each sodium thioglycolate solvent at $35^{\circ} \mathrm{C}$ for 24 $h r$ in a test tube with a screw cap. The reaction mixture was centrifuged at $18,000 \mathrm{rpm}$ for $20 \mathrm{~min}$. The precipitate was washed threc times with distilled water, dried and weighed to calculate the extractability.

The supernatant from TG/G-7 extraction was col-

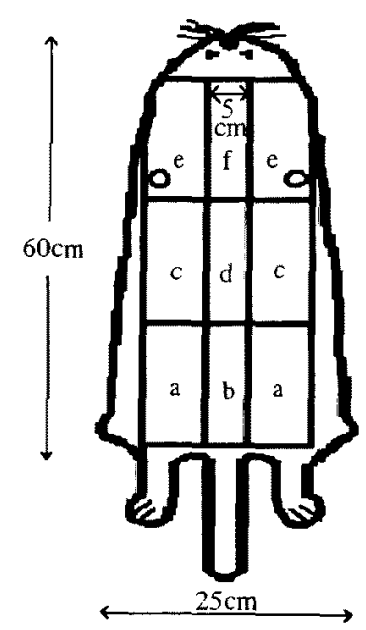

Fig. 1. Sampling portion of sapphire mink fur. lected, dialyzed against $0.1 \%$ mercaptoethanol solution (adjusted $\mathrm{pH} 7$ with ammonia) and lyophylized to examine the properties of protein.

\section{Xenon arc irradiation ${ }^{7)}$}

The hair sample separated from skin was irradiated with $2.5 \mathrm{~kW}$ xenon arc from a fade meter (Atlas Electric) for $96 \mathrm{hr}$ in a polyethylene bag (about 92 $87 \%$ passage in the wavelength from 900 to $280 \mathrm{~nm}$ ). This irradiation condition was adopted to elucidate the difference between underfur and guard hair which received the same irradiation as the basic experiment.

Borosilicate glass filter (inner and outer) was used to mimic the energy distribution of sunlight.

\section{SDS-PAGE of extracted protein ${ }^{3)}$}

Extracted protein samples were analyzed by sodium dodecyl sulphate-polyacrylamide gel electrophoresis (SDS-PAGE) using the method of Laemmli ${ }^{4}$, thereafter were dissolved in buffer containing $0.2 \mathrm{M}$ Tris$\mathrm{HCl}, 2 \% \mathrm{SDS}, 20 \%$ glycerol and $50 \mathrm{mM}$ dithiothreitol (DTT) at $\mathrm{pH} 8.0$. SDS-PAGE was carried out on slab gel of $15 \%$ acrylamide concentration using buffer containing $0.0495 \mathrm{M}$ Tris, $0.384 \mathrm{M}$ glycine and 0.0035 M SDS. The gel was stained with Coomassie Blue.

Size exclusion chromatography (SEC) of extracted protein $^{3)}$

Size exclusion chromatography was performed on a column set (TSKgel G4000 SW $\mathrm{xL}$, TSKgel G 3000 $\mathrm{SW}_{\mathrm{XL}}$ and TSKgel G2000 SW $\mathrm{XL}, 7.8 \mathrm{~mm}$ I.D. $\times 30 \mathrm{~cm}$ respectively) connected in series. Elution was carried out at the flow rate of $0.5 \mathrm{ml} / \mathrm{min}$ and room temperature, using buffer containing $6 \mathrm{M}$ guanidine$\mathrm{HCl}$ and $1 \mathrm{mM}$ DTT at $\mathrm{pH} 7$. The eluate was monitored by the absorbance at $230 \mathrm{~nm}$.

\section{Amino acid analysis ${ }^{2}$}

One $\mathrm{mg}$ of protein sample was hydrolyzed in $1 \mathrm{ml}$ of $6 \mathrm{~N}$ hydrochloric acid at $110^{\circ} \mathrm{C}$ for $24 \mathrm{hr}$ and submitted to amino acid auto analysis. Peaks of unidentified amino acid on the chart were numbered in the order of elution as unknown 1 and unknown 2, and their molar concentrations were calculated as leucine residues

\section{Results and Discussion}

\section{Amino acid composition of whole hair}

It is known that the hair protein is mainly composed 
Thioglycolate Extracts of Irradiated Mink Hair

Table 1. Amino acids composition of sapphire mink hairs

\begin{tabular}{lcccc}
\hline Amino acids & $\begin{array}{c}\text { Intact } \\
\text { underfur }\end{array}$ & $\begin{array}{c}\text { Intact } \\
\text { guard hair }\end{array}$ & $\begin{array}{c}\text { Irradiated } \\
\text { underfur }\end{array}$ & $\begin{array}{c}\text { Irradiated } \\
\text { guard hair }\end{array}$ \\
\hline Cys-A & 1 & 1 & 8 & 5 \\
unknown-1 & 1 & 1 & 2 & 2 \\
Asp & 55 & 49 & 61 & 51 \\
Thr & 66 & 60 & 66 & 60 \\
Ser & 124 & 139 & 126 & 139 \\
Glu & 124 & 125 & 129 & 125 \\
Pro & 60 & 64 & 60 & 66 \\
Lan & 8 & 9 & 11 & 11 \\
Gly & 115 & 124 & 126 & 131 \\
Ala & 49 & 48 & 54 & 51 \\
1/2 Cys & 107 & 116 & 60 & 83 \\
Val & 45 & 45 & 46 & 48 \\
Met & 9 & 9 & 11 & 13 \\
Ile & 19 & 16 & 19 & 17 \\
Leu & 62 & 57 & 65 & 58 \\
Tyr & 36 & 31 & 35 & 32 \\
Phe & 20 & 17 & 23 & 19 \\
His & 10 & 10 & 13 & 12 \\
unknown-2 & 0 & 1 & 2 & 1 \\
Lys & 27 & 31 & 24 & 30 \\
Arg & 61 & 48 & 61 & 48 \\
\hline
\end{tabular}

Values are given as amino acid residues per 1,000 total residues.

of low-cystine component originated from microfibril, high-cystine and high-glycine-tyrosine components originated from matrix. And it is regarded that the difference in composition of whole hair among animal species comes mainly from the relative content of the components.

Amino acid composition of untreated mink hairs as shown in Table 1 indicates a substantial similarity to that of wool rather than cattle hair ${ }^{3)}$. However, the content of glycine in mink hair was higher than in wool suggesting a higher content of high-glycinetyrosine.

Amino acid composition of irradiated mink hair is shown in Table 1. No remarkable differences from that of the intact hair was observed except for the decrease in $1 / 2$ cystine and the increase in cysteic acid, lanthionine, and unidentified amino acid contents. These changes reflect the light deterioration which occurred in cystine residue preferentially ${ }^{2)}$.

\section{Extractability of protein}

For the intact hair, the amount of extracted protein of underfur and of guard hair indicated an approximately constant level irrespective of the sampling portion as shown in Fig. 2 and Fig. 3. The amount of extracted protein of underfur was higher than that of guard hair. The value of TG11 was the highest and that of TG/G-7 was close to this. The value of TG/ U-7 was very low. Figures 2 and 3 demonstrate that TG 11 or TG/G-7 dissolves mink hair effectively.

Both the underfur and guard hair in the irradiated hair showed remarkable decreases in the protein extractability in case of TG 11 and TG/G-7. These decreases suggest that the irradiated mink hair protein is further stabilized by additional intermolecular or interpeptide crosslinks due to light irradiation. The protein fraction greatly to be affected by light 


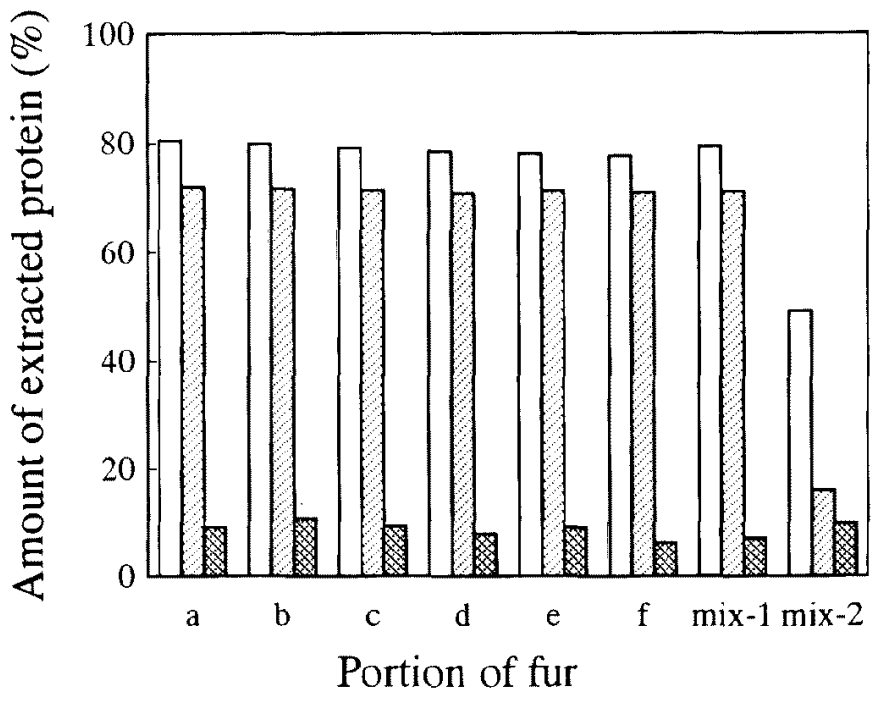

Fig. 2. Extractability of sapphire mink underfur with different sodium thioglycolate solutions compared to that of the different portions of fur. $\mathrm{a} \sim \mathrm{f}$ : sampling portion of fur shown in Fig. 1. mix-1 : mixed sample from a to $\mathrm{f}$.

mix-2 : irradiated mix-1 sample.

$\square: 0.1 \mathrm{M}$ sodium thioglycolate, $\mathrm{pH} 11,35^{\circ} \mathrm{C}, 24 \mathrm{hr}$. \%: $0.1 \mathrm{M}$ sodium thioglycolate $+6 \mathrm{M}$ guanidine $\mathrm{HCl}$, $\mathrm{pH} 7,35^{\circ} \mathrm{C}, 24 \mathrm{hr}$.

$: 0.1 \mathrm{M}$ sodium thioglycolate $+7 \mathrm{M}$ urea, $\mathrm{pH} 7$, $35^{\circ} \mathrm{C}, 24 \mathrm{hr}$.

irradiation must be contained in the fraction extractable with TG 11 or TG/G-7 from the intact hair. Therefore, protein extracted by TG/G-7 was examined in the following experiment.

\section{Amino acid composition of extracted protein}

As a whole, there was no remarkable difference in the amino acid composition between the whole hair (Table 1) and the extracted fraction (Table 2) of the intact hair, except that the latter indicated a smaller content of $1 / 2$ cystine and a larger content of tyrosine as compared with the former.

Both the underfur and the guard hair in the extracts of irradiated mink hairs, demonstrated a remarkable decrease in $1 / 2$ cystine compared with the intact hair extract. It is clear that at least a part of the decrease in $1 / 2$ cystine is due to the irradiation-induced destruction of the cystine residue viewing from the increase in lantionin and cysteic acid. On the other hand, the table demonstrates significant increases in

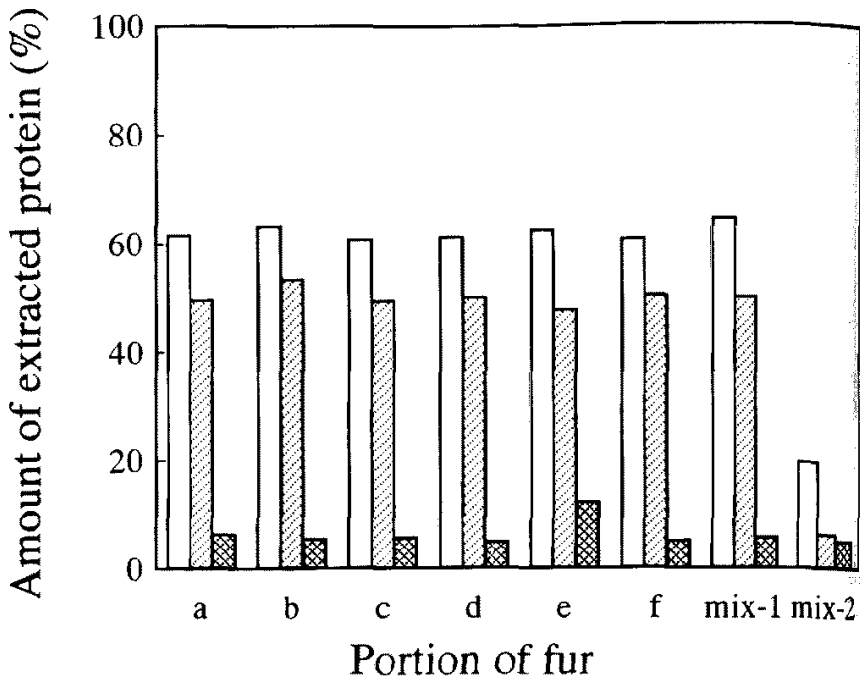

Fig. 3. Extractability of sapphire mink guard hair with different sodium thioglycolate solutions compared to that of the different portions of fur.

Abbreviations and symbols are same as in Fig. 2.

glycine, tyrosine and phenylalanine of the irradiated extract compared with the intact extract. This suggests that the high glycine-tyrosine protein in mink hair is more resistant to the irradiation in terms of the protein solubility.

Similar results have been reported on the protein extracted from the irradiated wool with alkaline DTT solution containing $8 \mathrm{M}$ urea $^{5)}$.

\section{SDS-PAGE of extracted protein}

The SDS-PAGE pattern of TG/G-7 extracts of the intact mink hairs showed that both underfur and guard hair had two distinct band groups at the position of $45 \mathrm{kDa}$ and $60 \mathrm{kDa}$ as shown in Fig. 4. These bands are observed in the reductive extract of wool and bovine hair ${ }^{3)}$, indicating the presence of microfibril origin protein. On the other hand, the composition of matrix origin proteins of hair is more complicated than that of microfibril origin protein. Thus the complicated band composition in the region below $20 \mathrm{kDa}$ in extracts of intact underfur and guard hair indicates the presence of matrix origin protein ${ }^{5)}$. In strong contrast to intact hair, extracts from irradiated hair indicate a dramatically diminished bands in the region above $15 \mathrm{kDa}$ and strongly concentrated bands in the region below $10 \mathrm{kDa}$ which correspond to those 
Thioglycolate Extracts of Irradiated Mink Hair

Table 2. Amino acids composition of TG/G-7 extracts from intact and irradiated mink hairs

\begin{tabular}{lcccc}
\hline \hline Amino acids & $\begin{array}{c}\text { Intact } \\
\text { underfur }\end{array}$ & $\begin{array}{c}\text { Intact } \\
\text { guard hair }\end{array}$ & $\begin{array}{c}\text { Irradiated } \\
\text { underfur }\end{array}$ & $\begin{array}{c}\text { Irradiated } \\
\text { guard hair }\end{array}$ \\
\hline Cys-A & 3 & 3 & 5 & 7 \\
unknown-1 & 1 & 1 & 1 & 1 \\
Asp & 65 & 65 & 64 & 67 \\
Thr & 70 & 68 & 54 & 51 \\
Ser & 100 & 103 & 101 & 102 \\
Glu & 118 & 117 & 67 & 69 \\
Pro & 64 & 64 & 66 & 69 \\
Lan & 18 & 18 & 23 & 28 \\
Gly & 106 & 111 & 186 & 185 \\
Ala & 54 & 53 & 40 & 43 \\
1/2 Cys & 70 & 69 & 34 & 21 \\
Val & 50 & 44 & 39 & 40 \\
Met & 10 & 10 & 7 & 6 \\
Ile & 25 & 22 & 18 & 19 \\
Leu & 71 & 72 & 64 & 69 \\
Tyr & 45 & 47 & 94 & 81 \\
Phe & 24 & 25 & 49 & 50 \\
His & 12 & 14 & 16 & 22 \\
unknown-2 & 0 & 1 & 1 & 2 \\
Lys & 25 & 24 & 15 & 18 \\
Arg & 69 & 68 & 54 & 46 \\
\hline Values & & & & \\
\hline
\end{tabular}

Values are given as amino acid residues per 1,000 total residues.

of intact hairs.

This suggests that the irradiation preferentially makes microfibril protein insoluble and largely leaves high-glycine-tyrosine component in matrix protein soluble. Therefore, the amino acids composition of the extract of irradiated hair is consistent with the suggestion since it contained a larger amount of glycine, tyrosine and phenylalanine.

\section{SEC of extract protein}

The SEC pattern of TG/G-7 extract of intact guard hair is shown in Fig. 5. Almost the same elution profile was obtained for the extracts of underfur. Compared with SDS-PAGE pattern, the SEC peaks a to $c$ are considered to correspond to microfibril proteins and peak $d$ to matrix potein. Calculation of the sum area ratio of peaks a to c to peak d gave $54 \%$ of the presumed content for microfibril protein and $46 \%$ for matrix protein.

The peaks which correspond to microfibril protein in the extract of irradiated guard hair was almost absent, and the dominant peaks of matrix protein were clearly observed as shown in Fig. 6. The d-1 peak of matrix protein decreased and the $\mathrm{d}-2$ peak remarkably increased. Similar tendency was observed in the underfur. Consequently, together with the results of SDS-PAGE and amino acid analysis, SEC demonstrates that the irradiation of mink hair preferentially makes microfibril protein insoluble, and leaves matrix protein, especially high-glycine-tyrosine component soluble. However the present data provides no information on the mechanism involved in the protein insolubilization. 


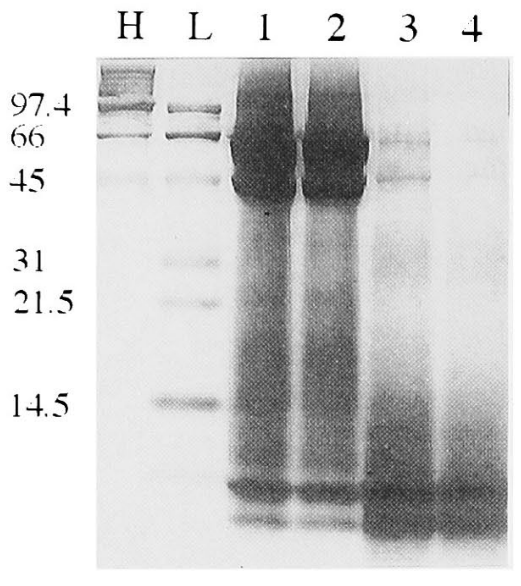

Fig. 4. SDS-PAGE of TG/G-7 extracts of intact and irradiated mink hairs.

$\mathrm{H}, \mathrm{L}$ : molecular weight standards

1 : underfur of sapphire mink

2 : guard hair of sapphire mink

3 : irradiated underfur of sapphire mink

4 : irradiated guard hair of sapphire mink

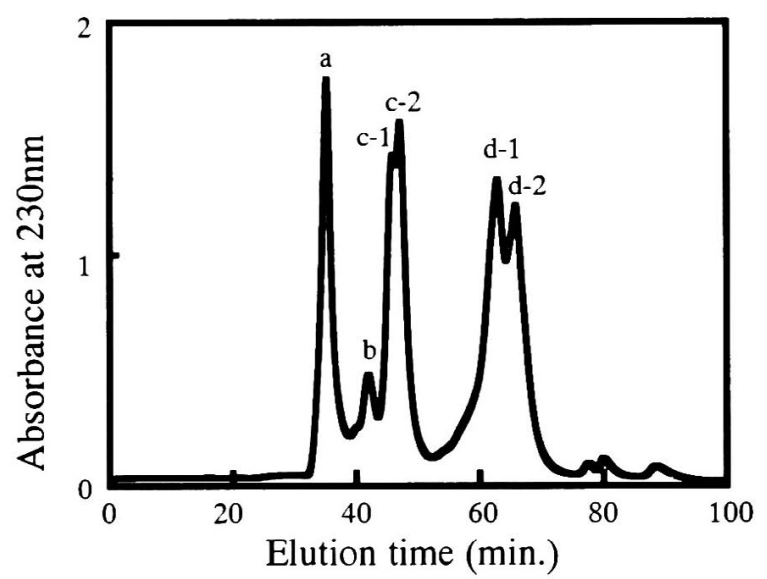

Fig. 5. Size exclusion chromatography of TG/G-7 extract of sapphire mink guard hair.

Peaks were labelled as a to $\mathrm{d}$.

Elution time of peak

$$
\begin{array}{ll}
\mathrm{a}: 35 \mathrm{~min} . & \mathrm{b}: 42 \mathrm{~min} . \\
\mathrm{c}-1: 46 \mathrm{~min} . & \mathrm{c}-2: 47 \mathrm{~min} . \\
\mathrm{d}-1: 63 \mathrm{~min} . & \mathrm{d}-2: 66 \mathrm{~min} .
\end{array}
$$

\section{Conclusion}

Over $50 \%$ of the green skin sapphire mink hair protein treated with sodium thioglycolate solutions,

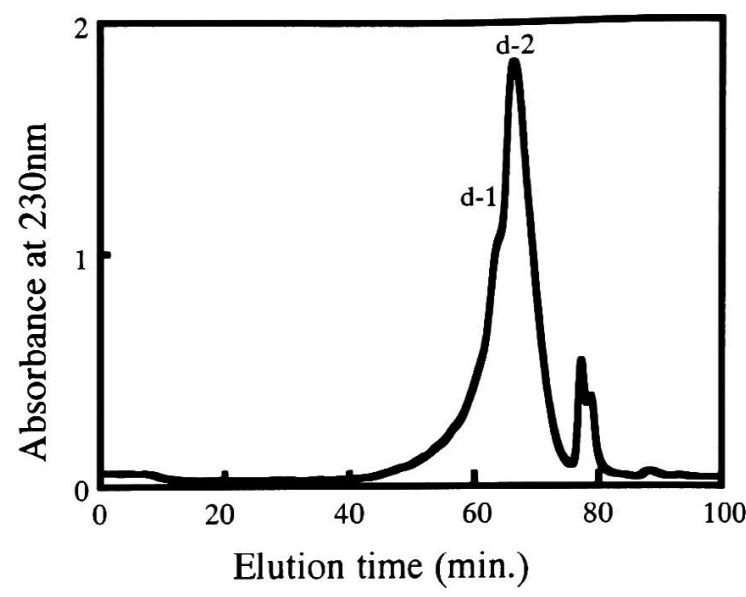

Fig. 6. Size exclusion chromatography of TG/G-7 extract of irradiated sapphire mink guard hair.

Peaks were labelled as d-1 and d-2.

Elution time of peak

d-1 $: 65$ min. d-2:67 min.

TG 11 and TG/G-7 was dissolved, but the extract with TG/U-7 was hardly dissolved. The extractability of underfur was higher than that of guard hair with TG 11 or TG/G-7. There was a remarkable decrease in extractability with TG 11 or TG/G-7 of the intact hair than of the irradiated hair. This implies that the irradiation-induced deterioration of mink hair involves the formation of some additional intermolecular or interpeptide crosslinks other than the original disulfide bridges in native hair.

Amino acid analysis, SDS-PAGE and SEC of TG/ G-7 extract revealed that the irradiation of mink hair made preferentially microfibril protein insoluble, and leaves matrix protein especially high-glycine-tyrosine component soluble.

\section{References}

1) Harrap BS, Gillespie JM. A further study on the extraction of reduced proteins from wool. Australian Journal of Biological Science, 16 : 542-557. 1963.

2) Imai $T$, Shirai $K$. Amino acid composition of fur after degradation : changes in amino acid composition of fur after artificial degradation treatments. The Journal of The American Leather Chemists Association, 89 : 132-140. 1994.

3) Kamal AMS, Nomura Y, Ishii $Y$, Shirai $K$. Properties of bovine hair keratins solubilized with 
Thioglycolate Extracts of Irradiated Mink Hair

thioglycolate. The Journal of The American Leather Chemists Association, 93 : 272-282. 1998.

4) Laemmli UK. Cleavage of structural proteins during the assembly of the head of bacteriophage T4. Nature, 227.: 680-685. 1970.

5) Leaver IH, Marshall RC, Rivett DE. Light-induced changes in the composition of wool and lysozyme. Proceedings of The 7 th International Wool Textile Research Conference, 4 : 11-20. 1985.
6) Matsunaga A, Uehara K, Toyoda H. Solubilization of human hair keratin by reduction with sodium thioglycolate. Hikaku Kagaku, 30:39-47. 1984.

7) Terashima M, Imai T, Chonan $Y$, Shirai K. Evaluation of the deterioration in mink hair under xenon arc irradiation by fourier transform infrared (FTIR) microspectroscopy. SEN'I GAKKAISHI, 54:354359. 1998. 